School of Social Policy, University of Birmingham, Birmingham B15 2TT, UK Health Services Management Centre, University of Birmingham

j.glasby@bham.ac.uk Cite this as: BMJ2020;370:m3103 http://dx.doi.org/10.1136/bmj.m3103 Published: 12 August 2020

\section{The neglect of adult social care during covid-19}

\section{Discharging untested patients to care homes was an "appalling error," says parliamentary report}

\section{Jon Glasby, Catherine Needham}

The government's response to covid-19 has triggered excoriating critiques, but the tone of the recent Public Accounts Committee (PAC) report on adult social care is nonetheless remarkable. ${ }^{1}$ Focusing particularly on failings in testing and personal protective equipment (PPE), it states that "discharging patients from hospital into social care without first testing them for covid-19 was an appalling error" and that policy relating to PPE was "reckless and negligent." Ironically, the hard hitting PAC report was followed closely by the announcement that regular testing for care home residents and staff, promised from 6 July, would now be delayed until later in the year. ${ }^{2}$

Over 30500 excess deaths have been reported in care homes in England since March. ${ }^{3}$ PAC focuses on the discharge of 25000 untested patients into care homes between mid-March and mid-April, denouncing the government's handling of this. It notes that we still do not know which care homes received discharged patients and how many subsequently had outbreaks. It asks for this information to be provided by September.

This is not the fault of individual clinicians, who were told to "discharge urgently all medically fit hospital patients with covid-19 to maximise inpatient and critical care" ${ }^{1}$ and were facing intense and unprecedented pressures. As David Oliver notes, tests at that time were not only scarce but also unreliable, making it hard to envisage a situation in which they could have been used more effectively. ${ }^{4}$ Nonetheless, PAC is clear that poor national decisions were compounded by earlier failings in pandemic preparedness and a sluggish policy response as covid-19 gathered pace in January and February.

Access to PPE was similarly subject to delays, highlighting a failure to include social care in the planning that was carried out for the NHS. An action plan for social care was published only on 15 April; before this, the sector was expected to procure its own PPE. "This was against a background of the NHS's huge purchasing power and tightening domestic and worldwide demands for PPE." ${ }^{\text {As }}$ Martin McKee writes in The BMJ, Johnson's later claim that care homes hadn't followed procedures regarding PPE were seen by the sector as "a Kafkaesque alternative reality." 5 The PAC report also contradicts the secretary of state's reference to the "protective ring that we've cast around all our care homes."6

Cross national analysis of deaths in care homes indicates that care home residents were more likely to die from covid-19 in the UK than in any other major European country, apart from Spain. ${ }^{7}$ But reporting differences hamper these comparisons, and the World Health Organization has found that many countries failed to support their long term care sectors effectively. ${ }^{8}$ Domiciliary care, which supports more people than care homes, is often left out of the story altogether (and not mentioned directly in the PAC report), partly because the data are so poor. ${ }^{3}$ Most of the debate to date has been about older people, without considering the experiences of people of working age (representing around half of social care's annual expenditure).

\section{Complex, fragmented}

One of the reasons why central, top-down approaches tend not to work in adult social care (if they work anywhere) is that the sector is much more complex and fragmented than many people realise. Around 1.5 million people are working in adult social care in England, with roles spread across the public, private, and voluntary sectors (and with most staff employed by some 18500 small and medium sized private providers). ${ }^{9}$ Some 145000 roles are directly employed by individuals who design and commission their own care through mechanisms such as direct payments.

Against this background, recent media speculation of the NHS "taking over" social care ${ }^{10}$ might move the overall boundaries of current services and responsibilities but wouldn't solve these underlying complexities. There is also no evidence that the NHS would be any better at managing this complexity than local government (and probably quite a lot of evidence that it might be worse). As the King's Fund argues, talk of potential takeovers arguably misses the point as social care isn't about medical interventions but about a type of care, support, and philosophy that isn't a strength of the NHS. ${ }^{11}$

PAC focuses on the response to the pandemic as part of a longer term neglect, noting the "tragic impact of delaying much needed social care reform, and instead treating the sector as the NHS's poor relation." If any good is to come from such tragedy, we must renew our efforts to achieve a lasting settlement for social care, understanding and valuing it in its own right, not just as an adjunct to the NHS. If nothing else, we owe it to all the people who have died, their families, and the care staff who tried so hard to keep them safe.

Provenance: Not commissioned, not externally peer reviewed.

Competing interests: We have read and understood BMJ policy on declaration of interests and have no relevant interests to declare.

Public Accounts Committee. Readying the NHS and social care for the COVID-19 peak. 2000: https://committees.parliament.uk/committee/127/public-accounts-committee/news/147605/slow-inconsistent-and-negligentapproach-to-social-care-in-pandemic/.

2 Gregory A, Shipman T, Pogrund G, Das S. Care home coronavirus testing pledge abandoned. Times 2020 Aug 2. https://www.thetimes.co.uk/article/care-home-coronavirus-testing-pledge-abandoned-tqxf6mm6j 
3 Health Foundation. Adult social care and COVID-19: assessing the impact on social care users and staff in England so far. 2020. www.health.org.uk/publications/report/adult-social-care-andcovid-19-assessing-the-impact-on-social-care-users-and-staff-in-england-so-far

4 Oliver D. Heresy warning: re care home COVID deaths. 2020. https://threadreaderapp.com/thread/1262982297357365253.html.

5 McKee M. England's PPE procurement failures must never happen again. BM/2020;370:m2858. doi: 10.1136/bmj.m2858 pmid: 32680840

6 BBC News. Matt Hancock on testing for care home staff and residents. 19 May 2020. www.bbc.co.uk/news/av/uk-politics-52725547/matt-hancock-on-testing-for-care-home-staffand-residents

7 Comas-Herrera A, Zalakaín J, Litwin C, et al. Mortality associated with COVID-19 outbreaks in care homes: early international evidence. International Long-term Care Policy Network. 26 June 2020. https://tccovid.org/wp-content/uploads/2020/06/Mortality-associated-with-COVID-amongpeople-who-use-long-term-care-26-June.pdf

8 World Health Organization. Preventing and managing COVID-19 across long-term care services: policy brief. 2020. https://www.who.int/publications/i/item/WHO-2019-nCoV-Policy_Brief-Longterm_Care-2020.1.

9 King's Fund. Key facts and figures about adult social care. 2019. www.kingsfund.org.uk/audiovideo/key-facts-figures-adult-social-care.

10 Campbell D. Revealed: NHS could take over social care, swelling budget to £150bn. Guardian 27 July 2020. www.theguardian.com/society/2020/jul/27/revealed-social-care-nhs-swelling-budgetcamilla-cavendish

11 Warren S. Social care reform: fit for purpose or simply fit for a crisis? London: King's Fund, 14 May, 2020. www.kingsfund.org.uk/blog/2020/05/social-care-reform-fit-purpose-or-crisis 